\title{
Emergency department visits and hospitalizations by tube-fed nursing home residents with varying degrees of cognitive impairment: a national study
}

\author{
Caroline E Stephens ${ }^{1,2^{*}}$, Nathan Sackett ${ }^{3}$, Prasanthi Govindarajan ${ }^{4}$ and Sei J Lee ${ }^{2}$
}

\begin{abstract}
Background: Numerous studies indicate that the use of feeding tubes (FT) in persons with advanced cognitive impairment (Cl) does not improve clinical outcomes or survival, and results in higher rates of hospitalization and emergency department (ED) visits. It is not clear, however, whether such risk varies by resident level of $\mathrm{Cl}$ and whether these ED visits and hospitalizations are potentially preventable. The objective of this study was to determine the rates of ED visits, hospitalizations and potentially preventable ambulatory care sensitive (ACS) ED visits and ACS hospitalizations for long-stay $\mathrm{NH}$ residents with FTs at differing levels of $\mathrm{Cl}$.
\end{abstract}

Methods: We linked Centers for Medicare and Medicaid Services inpatient \& outpatient administrative claims and beneficiary eligibility data with Minimum Data Set (MDS) resident assessment data for nursing home residents with feeding tubes in a 5\% random sample of Medicare beneficiaries residing in US nursing facilities in 2006 ( $n=3479$ ). Severity of $\mathrm{Cl}$ was measured using the Cognitive Performance Scale (CPS) and categorized into 4 groups: None/Mild $(C P S=0-1, M M S E=22-25)$, Moderate $(C P S=2-3, M M S E=15-19)$, Severe $(C P S=4-5, M M S E=5-7)$ and Very Severe $(C P S=6, M M S E=0-4)$. ED visits, hospitalizations, ACS ED visits and ACS hospitalizations were ascertained from inpatient and outpatient administrative claims. We estimated the risk ratio of each outcome by $\mathrm{Cl}$ level using over-dispersed Poisson models accounting for potential confounding factors,

Results: Twenty-nine percent of our cohort was considered "comatose" and "without any discernible consciousness", suggesting that over 20,000 NH residents in the US with feeding tubes are non-interactive. Approximately $25 \%$ of $\mathrm{NH}$ residents with $\mathrm{FTs}$ required an ED visit or hospitalization, with $44 \%$ of hospitalizations and $24 \%$ of ED visits being potentially preventable or for an ACS condition. Severity of CI had a significant effect on rates of ACS ED visits, but little effect on ACS hospitalizations.

Conclusions: ED visits and hospitalizations are common in cognitively impaired tube-fed nursing home residents and a substantial proportion of ED visits and hospitalizations are potentially preventable due to ACS conditions.

Keywords: Tube feeding, Cognitive impairment, Nursing home, Emergency department, Hospitalization, Ambulatory care sensitive

\footnotetext{
* Correspondence: Caroline.stephens@ucsf.edu

1 Department of Community Health Systems, University of California San

Francisco, 2 Koret Way, \#N531E, San Francisco, CA 94143-0608, USA

${ }^{2}$ Division of Geriatrics, Palliative \& Extended Care, UCSF/San Francisco VA

Medical Center, 4150 Clement St, San Francisco, CA 94121, USA

Full list of author information is available at the end of the article
} 


\section{Background}

Cognitively impaired nursing home residents are a large and growing segment of the Medicare population who often require acute care services such as emergency department (ED) visits and hospitalizations. In 2009, 68\% of all nursing home residents had some degree of cognitive impairment $(\mathrm{CI})$ [1], with the number of persons with CI expected to triple by 2050 [2]. Further, cognitively impaired nursing home residents are at increased risk for potentially preventable hospitalizations and ED visits [3-5]. Thus, the population of cognitively impaired nursing home residents will continue to grow rapidly and will likely continue to require frequent acute care services.

Unfortunately, CI is usually progressive, frequently leading to feeding problems and dysphagia [6]. When this occurs, providers and families face the difficult decision regarding feeding tube (FT) placement for artificial hydration and nutrition. Although there is no evidence that the use of FTs improves clinical outcomes or survival in this patient group [7-11], the practice is incredibly common with as many as $34 \%$ of nursing home $(\mathrm{NH})$ residents with severe CI having a FT [12]. This may be due in part to the perception by physicians and families that FT placement has minimal risks or burdens $[13,14]$. However, studies suggest that $\mathrm{NH}$ residents with FTs are at increased risk for hospitalizations [15] and ED visits [3,4], compared to those without FTs. One recent study found that $26 \%$ of tube fed $\mathrm{NH}$ residents had a potentially preventable ED visit [4]. Frequent hospital transfers in this already vulnerable population often leads to greater cognitive and functional decline, delirium, iatrogenic complications and death $[16,17]$.

Studies to date on the relationship between ED visits and hospitalizations in NH residents with FTs have focused on those with advanced dementia. Little is known about whether the risk of acute care utilization in $\mathrm{NH}$ residents with FTs varies by the severity of their CI and whether these ED visits and hospitalizations are potentially preventable. Such information may give families and providers a clearer picture of the likely burdens associated with FT use based on cognitive status and allow them to make a more informed care decision about initial feeding tube placement. Thus, our objective was to determine the rates of ED visits and hospitalizations by differing levels of $\mathrm{CI}$ among a national random sample of $\mathrm{NH}$ residents with FTs. Further, we examined the rates of potentially preventable ED visits and hospitalizations by determining the rates of Ambulatory Care Sensitive (ACS) ED visits and ACS hospitalizations.

\section{Methods}

Study design

We conducted a retrospective cohort study utilizing 2006 Centers for Medicare and Medicaid Services (CMS) inpatient and outpatient administrative claims and beneficiary eligibility data linked with nursing home resident assessment data. This research study was approved by the University of California, San Francisco's Committee on Human Research.

\section{Study setting and population}

We examined a 5\% random sample of all Medicare feefor-service beneficiaries over the age of 65 residing in U.S. nursing homes in 2006 from the Centers for Medicare and Medicaid Services (CMS) Chronic Condition Data Warehouse standard analytic file (for CMS standard sampling strategy: https://www.ccwdata.org/web/guest/userdocumentation). $\mathrm{NH}$ residence was determined by the presence of a Minimum Data Set (MDS) 2.0 assessment in 2006. We focused on NH residents with FTs, only including residents whose MDS item K5b, "Nutritional Approaches: Feeding tube?" was checked. We excluded residents receiving hospice $(n=77)$ and those with missing cognitive or covariate data $(n=53)$, leading to our final analytic sample of $3479 \mathrm{NH}$ residents with FTs. Since we were specifically interested in the rates of acute care utilization by long stay $\mathrm{NH}$ residents, we measured outcomes after a 90-day blackout window after initial $\mathrm{NH}$ assessment to exclude short-stay residents.

\section{Primary predictor}

The primary predictor of interest was level of $\mathrm{CI}$ as defined by the Cognitive Performance Scale (CPS). The CPS is a 7-point hierarchical scale derived from the Minimum Data Set (MDS) that rates CI from 0 (no impairment) to 6 (very severe impairment) and has been widely used as a valid measure of cognition in previous studies of $\mathrm{NH}$ residents [18-20]. The 5 MDS items used in this scale include: Comatose Status, Short-Term Memory, Cognitive Skills for Daily Living, Making Self Understood by Others, and Activities of Daily Living (ADL) Self-Performance in Eating. Previous validation studies suggest that the CPS is tightly correlated with other cognitive scales, including the Mini-Mental Status Exam (MMSE) [18,19,21-23].

For this study, we categorized severity of CI into 4 groups: No/Mild (0, 1); Moderate (2, 3); Severe $(4,5)$; Very Severe (6). NH residents in the No/Mild category (CPS 0,1) are considered intact or borderline intact with Folstein Mini-Mental Status Exam (MMSE) scores of 22 to 25 [24]. NH residents in the Moderate impairment category (CPS 2,3) have been shown to have MMSE scores of 15 to 19 . NH residents in the Severe impairment category (CPS 4,5) have been shown to have MMSE scores of 5 to 7 . NH residents in the Very Severe category (CPS 6) have profound impairment and are characterized as being "comatose" or showing "no discernible consciousness" with an MMSE of 0 to 4. Since our focus was on the majority of tube-fed $\mathrm{NH}$ residents 
with $\mathrm{CI}$, we chose the Moderate CI group as our reference category rather than the No/Mild CI group.

\section{Primary outcomes}

Inpatient and outpatient claims data were used to examine the rates of the following 4 outcomes: 1) ED Visit; 2) ACS ED Visit; 3) Hospitalization; 4) ACS Hospitalization. The $E D$ visit outcome was defined as any ED visit that did not result in a hospitalization using the Outpatient Standard Analytic File (SAF) (revenue center codes 0450-0459 and 0981). The ACS ED Visit outcome was defined as any ED visit that did not result in a hospitalization, but had an ACS condition listed as the primary (final) reason for the ED stay. To classify visits as ACS, we used the Agency for Healthcare Research and Quality's (AHRQ) "Prevention Quality Indicators" (PQIs) that aim to identify ACS conditions based on ICD-9 codes [25]. This AHRQ methodology is widely accepted and has been used extensively in previous literature as an indicator of potentially preventable hospitalizations and ED visits [26-28]. These are standardized measures based on ACS condition classifications $[29,30]$ and have been validated and commonly used in prior studies of ACS acute care utilization among elderly long term care residents [28,31-33]. The Hospitalization outcome was defined as any hospitalization as identified in the Medicare Provider Analysis and Review (MEDPAR) file (short, long, skilled nursing facility stay indicator code = S). The ACS Hospitalization outcome was defined as any hospitalization for an ACS condition listed as the primary reason for the hospital stay in the MEDPAR file. If K5b (feeding tube present) was 'yes' on any qualifying MDS assessment then the resident was considered to be at risk for any of the above outcomes through death or the end of calendar year 2006.

\section{Possible confounding factors}

We examined several widely used MDS resident variables to adjust for potential differences in sociodemographic characteristics and disease severity [20,34-39]. Selected characteristics included sociodemographic variables (age, sex, race/ethnicity, marital status), previously diagnosed medical illnesses or conditions (stroke, any stage 2+ pressure ulcer), level of ADL impairment, and certain treatments/preferences (Do Not Resuscitate order, any use of a urinary catheter). Age was coded into 3 categories: 65 to 75 years, 76 to 85 years, and $86+$ years. Similar to previous studies, we included race/ethnicity as a categorical variable (as captured in the MDS) as evidence suggests that FT placement differs by race/ethnicity [9]. Due to small numbers of Hispanics, Asians, Pacific Islanders, and Native Americans, these race/ethnicity categories were collapsed into a single category of "other". Since no prior investigations have specifically examined a cohort of only tube-fed residents (vs general
$\mathrm{NH}$ population), we selected ADLs and constructed ADL categories that were both clinically meaningful and reasonably distributed across our $5 \%$ national random sample of tube-fed nursing home residents. Specifically, level of Activities of Daily Living (ADL) Impairment was determined by summing the observed physical function ratings in each of 5 ADLs (Eating, Toileting, Bathing, Dressing and Transferring) examined in the MDS. Each ADL was rated on a scale of 0 (total independence) to 4 (total dependence), leading to a total ADL score ranging from 0 to 20. We collapsed the ADL data into the following 4 categories: Independent- Limited ADL Assistance (score 0-12); Extensive ADL Assistance (score 13-17); Total Dependence in Most ADLs (score 18-19); Total Dependence in all ADLs (score 20). The MDS-Changes in Health, End-stage disease and Symptoms and Signs (CHESS) scale, was used to account for overall health status [40].

\section{Data analysis}

Descriptive statistics were used to characterize the sample of $\mathrm{NH}$ residents by the severity of their CI. Frequency, percent and measures of central tendency were employed to summarize the characteristics of the sample and evaluate the data. Frequency counts, chi-square and Kruskal-Wallis test $\mathrm{p}$-values were calculated to compare the proportion of patients by the severity of their CI. Nominal variables have a chi-square $\mathrm{p}$-value and ordered variables have a nonparametric Kruskal-Wallis test p-value.

We then examined the distribution of possible confounding factors and outcomes across levels of CI. Descriptive statistics suggested overdispersed count data leading us to utilize overdispersed Poisson models to estimate the unadjusted and adjusted incident rate ratio (IRR) of each of the outcomes by level of CI. Since NH residents with MDS evaluations early in the year are at risk for acute care needs for a longer time period than $\mathrm{NH}$ residents with MDS evaluations later in the year, we included an exposure offset in our models, and present our outcomes in person-years of observation with 95\% confidence intervals. All analyses were performed using SAS version 9.2 (SAS Institute, Inc., Cary, NC).

\section{Results}

In our study, we found $3479 \mathrm{NH}$ residents had feeding tubes, suggesting that nearly $70,000 \mathrm{NH}$ residents in the US were tube-fed in 2006. Table 1 shows the sociodemographic characteristics of $\mathrm{NH}$ residents with FTs by level of CI. Twenty-nine percent $(1003 / 3479)$ of $\mathrm{NH}$ residents with FTs had Very Severe CI and were considered "comatose" or having "no discernible consciousness". Since our analytic sample represents a random 5\% sample of Medicare beneficiaries, this result suggests that over 20,000 US NH residents with FTs were "comatose" or had "no discernible consciousness" in 2006. Most 
Table 1 Characteristics of nursing home residents with feeding tubes and characteristics by level of cognitive impairment $(\mathrm{Cl})^{1}{ }^{*}$

\begin{tabular}{|c|c|c|c|c|c|}
\hline Characteristic & $\begin{array}{l}\text { Total sample } \\
(\mathrm{n}=3479), \%\end{array}$ & $\begin{array}{l}\text { No/Mild Cl } \\
(n=785), \%\end{array}$ & $\begin{array}{c}\text { Mild/Moderate Cl } \\
(n=1109), \%\end{array}$ & $\begin{array}{l}\text { Moderate/Severe Cl } \\
\quad(n=582), \%\end{array}$ & $\begin{array}{c}\text { Very severe } \mathrm{Cl} \\
(\mathrm{n}=1003), \% \\
\end{array}$ \\
\hline \multicolumn{6}{|l|}{ Sociodemographics } \\
\hline \multicolumn{6}{|l|}{ Sex } \\
\hline Male & 46 & 48 & 49 & 46 & 40 \\
\hline Female & 54 & 52 & 51 & 54 & 60 \\
\hline \multicolumn{6}{|l|}{ Race/Ethnicity } \\
\hline White & 73 & 86 & 79 & 70 & 58 \\
\hline Black & 19 & 10 & 16 & 20 & 28 \\
\hline Other & 8 & 4 & 5 & 10 & 14 \\
\hline \multicolumn{6}{|l|}{ Age group } \\
\hline $65-75$ & 27 & 36 & 25 & 24 & 25 \\
\hline $76-85$ & 47 & 47 & 49 & 47 & 44 \\
\hline $86+$ & 26 & 17 & 25 & 30 & 31 \\
\hline Married & 40 & 44 & 41 & 39 & 36 \\
\hline \multicolumn{6}{|l|}{ Resident diagnoses \& conditions } \\
\hline CVA & 38 & 18 & 36 & 49 & 51 \\
\hline Stage $2+$ pressure ulcer & 37 & 29 & 35 & 33 & 48 \\
\hline \multicolumn{6}{|l|}{ ADL impairment level ${ }^{2}$} \\
\hline Independent-limited ADL & 9 & 28 & 8 & 1 & 0 \\
\hline \multicolumn{6}{|l|}{ Assistance (0-12) } \\
\hline Extensive ADL assistance (13-17) & 32 & 49 & 44 & 30 & 5 \\
\hline Total dependence in most ADLs (18-19) & 17 & 11 & 21 & 25 & 12 \\
\hline Total dependence in all ADLs (20) & 42 & 13 & 26 & 43 & 83 \\
\hline \multicolumn{6}{|l|}{ CHESS category } \\
\hline Mild (0) & 20 & 15 & 19 & 22 & 26 \\
\hline Moderate (1-3) & 75 & 85 & 75 & 73 & 69 \\
\hline Severe (4-5) & 4 & $<1$ & 6 & 5 & 5 \\
\hline \multicolumn{6}{|l|}{ Treatments \& preferences } \\
\hline Do not resuscitate order & 33 & 24 & 33 & 37 & 39 \\
\hline Any urinary catheter use & 48 & 39 & 45 & 53 & 57 \\
\hline
\end{tabular}

${ }_{1}^{1}$ Cognitive status measured by the Cognitive Performance Scale (CPS) - No/Mild (0, 1); Mild/Moderate (2, 3); Moderate/Severe (4, 5), Very Severe (6).

${ }^{2} \mathrm{ADL}$ Impairment Level is a composite measure of 0-4 level of impairment for each ADL of transferring, dressing, toileting, bathing, and eating yielding a total possible score of 20 (representing total dependence in ADLs). We defined 4 categories of ADL Impairment: Independent- Limited ADL Assistance (score 0-12); Extensive ADL Assistance (score 13-17); Total Dependence in Most ADLs (score 18-19); Total Dependence in all ADLs (score 20).

*All characteristics were significantly different across all 4 levels of $\mathrm{Cl}(\mathrm{p}<.0001)$.

participants were female (54\%), and almost $20 \%$ were African American. NH residents with FTs in this study sample also had profound ADL impairment with $42 \%$ reporting dependence in all ADLs, representing nearly 30,000 US NH residents who are completely dependent in all ADLs (toileting, transferring, eating, dressing and bathing).

Table 2 shows the results of our overdispersed Poisson regression that modeled the rates of ED visits and ACS ED Visits among this national random sample of $\mathrm{NH}$ residents with feeding tubes. Ten percent of $\mathrm{NH}$ residents with FTs required an ED visit and $2.3 \%$ had a potentially preventable ACS ED visit in 2006. Twentyfour percent (79/335) of all ED visits by $\mathrm{NH}$ residents with FTs were considered potentially preventable and due to an ACS condition. Overdispersed poisson models revealed that $\mathrm{NH}$ residents with moderate/severe $\mathrm{CI}$ had significantly higher rates of ED and ACS ED visits compared to those with mild/moderate CI [IRR $=1.42(1.16$ 1.74) and IRR $=1.80(1.35-2.41)$, respectively]. In contrast, $\mathrm{NH}$ residents with very severe $\mathrm{CI}$ had similar adjusted rates of ED visits and ACS ED visits as NH residents with mild/moderate CI $[\mathrm{IRR}=1.05(.85-1.30)$ and $\mathrm{IRR}=1.17$ (.87-1.57), respectively]. 
Table 2 Rates of ED Visits and ACS ED visits according to the characteristics of nursing home residents with feeding tubes

\begin{tabular}{|c|c|c|c|c|c|c|}
\hline \multirow[t]{2}{*}{ Characteristic } & \multirow[t]{2}{*}{$\begin{array}{l}\text { ED visit rate, } \\
\text { no. (\%) }\end{array}$} & \multicolumn{2}{|c|}{$\begin{array}{l}\text { ED visit incident rate ratios } \\
(95 \% \text { confidence interval })\end{array}$} & \multirow[t]{2}{*}{$\begin{array}{l}\text { ACS ED visit rate, } \\
\text { no. }(\%)\end{array}$} & \multicolumn{2}{|c|}{$\begin{array}{l}\text { ACS ED incident rate ratios } \\
\text { (95\% confidence interval) }\end{array}$} \\
\hline & & Unadjusted & Adjusted $^{+}$ & & Unadjusted & Adjusted $^{+}$ \\
\hline Total & $335(9.6)$ & & & $79(2.3)$ & & \\
\hline \multicolumn{7}{|c|}{ Severity of cognitive impairment ${ }^{1}$} \\
\hline No/Mild & $82(10.4)$ & $1.00(.83-1.20)$ & $.92(.76-1.11)$ & $24(3.1)$ & $1.79(1.37-2.33)^{* * *}$ & $1.84(1.40-2.41)^{* * *}$ \\
\hline Mild/Moderate & $105(9.5)$ & Ref & Ref & $21(1.9)$ & Ref & Ref \\
\hline Moderate/Severe & $65(11.2)$ & $1.35(1.10-1.65)^{* *}$ & $1.42(1.16-1.74)^{* *}$ & $14(2.4)$ & $2.02(1.50-2.71)^{* * *}$ & $1.80(1.35-2.41)^{* * *}$ \\
\hline Very severe & $83(8.3)$ & $.89(.73-1.08)$ & $1.05(.85-1.30)$ & $20(2.0)$ & $1.42(1.07-1.89)^{*}$ & $1.17(.87-1.57)$ \\
\hline
\end{tabular}

${ }^{+}$Adjusted for age, sex, race/ethnicity, marital status, diagnoses/conditions, level of ADL impairment, DNR order present, any urinary catheter use.

${ }^{1}$ Severity of Cognitive Impairment was measured by the Cognitive Performance Scale (CPS) - No/Mild (0, 1); Mild/Moderate (2, 3); Moderate/Severe (4, 5); Very Severe (6).

${ }^{*} \mathrm{p}<.01,{ }^{* *} \mathrm{p}<.001,{ }^{* * *} \mathrm{p}<.0001$.

Table 3 shows the results of our over dispersed Poisson regression that modeled the rates of hospitalizations and ACS hospitalizations. The hospitalization rate for $\mathrm{NH}$ residents with FTs in 2006 was $16 \%$ and the ACS hospitalization rate was $7 \%$. Forty-four percent (242/ 553) of all hospitalizations in this study sample were potentially preventable and due to an ACS condition. In contrast to our ED results, severity of CI did not have a significant effect on rates of hospitalizations.

\section{Discussion}

Examining a 5\% random sample of Medicare beneficiaries in 2006, we found that approximately $25 \%$ of $\mathrm{NH}$ residents with FTs required an ED visit or hospitalization, with 44\% of hospitalizations and 24\% of ED visits being potentially preventable for an ACS condition. Moreover, nearly 30\% of $\mathrm{NH}$ residents with FTs were considered "comatose" or without "discernible consciousness", representing 20060 $\mathrm{NH}$ residents with FTs in the US. We further found that $42 \%$ of $\mathrm{NH}$ residents with FTs were dependent in all ADLs, representing 31,700 $\mathrm{NH}$ residents who are unable to eat, bathe, toilet, transfer, or dress.
Previous studies suggest that there are little or no benefits to FTs in cognitively impaired patients, particularly among those with advanced dementia. Evidence suggests that FTs in cognitively impaired patients do not prevent aspiration pneumonia, improve function, prevent or improve pressure ulcers, reduce the risk of infection, meaningfully improve nutritional status, decrease weight loss, improve wound healing, improve patient comfort, or decrease mortality - all the reasons commonly cited to support FT placement $[6,7,10,11,20,41-47]$. Among our national sample of tube-fed $\mathrm{NH}$ residents, we found that nearly half were classified as having at least severe or very severe CI (CPS 4-6, MMSE $<7$ ).

Our results further indicate that the risks of hospitalization and ED visits vary by degree of CI. Tube-fed NH residents with severe CI (CPS 4-5, MMSE 5-7) are more likely to need ED evaluation than $\mathrm{NH}$ residents with moderate CI (CPS 2-3, MMSE 15-19) or very severe CI (CPS 6, MMSE 0-4). One possible explanation could be that $\mathrm{NH}$ staff, providers and families may recognize that ED visits may be especially burdensome for $\mathrm{NH}$ residents with profound $\mathrm{CI}$ and thus attempt to minimize ED visits for these residents. Alternatively, since NH residents with very

Table 3 Rates of hospitalizations and ACS hospitalizations according to the characteristics of nursing home residents with feeding tubes

\begin{tabular}{|c|c|c|c|c|c|c|}
\hline \multirow[t]{2}{*}{ Characteristic } & \multirow[t]{2}{*}{$\begin{array}{l}\text { Hospitalization } \\
\text { rate, no. (\%) }\end{array}$} & \multicolumn{2}{|c|}{$\begin{array}{l}\text { Hospitalization incident rate ratios } \\
\text { (95\% confidence interval) }\end{array}$} & \multirow[t]{2}{*}{$\begin{array}{l}\text { ACS Hosp rate, } \\
\text { no. (\%) }\end{array}$} & \multicolumn{2}{|c|}{$\begin{array}{l}\text { ACS Hosp incident rate ratios } \\
\text { (95\% confidence interval) }\end{array}$} \\
\hline & & Unadjusted & Adjusted $^{+}$ & & Unadjusted & Adjusted $^{+}$ \\
\hline Total & $553(15.9)$ & & & $242(6.9)$ & & \\
\hline \multicolumn{7}{|c|}{ Severity of cognitive impairment $^{1}$} \\
\hline No/Mild & $138(17.6)$ & $1.02(.88-1.91)$ & $1.13(.96-1.32)$ & $54(6.9)$ & $.99(.82-1.20)$ & $1.18(.97-1.44)$ \\
\hline Mild/Moderate & $167(15.1)$ & Ref & Ref & $85(7.7)$ & Ref & Ref \\
\hline Moderate/Severe & $94(16.2)$ & $1.03(.86-1.24)$ & $.98(.82-1.18)$ & $37(6.4)$ & $.95(.75-1.19)$ & $.89(.71-1.12)$ \\
\hline Very severe & $154(15.4)$ & $1.09(.92-1.27)$ & $.93(.78-1.10)$ & $66(6.6)$ & $.98(.81-1.20)$ & $.87(.70-1.09)$ \\
\hline
\end{tabular}

${ }^{+}$Adjusted for age, sex, race/ethnicity, marital status, diagnoses/conditions, level of ADL impairment, DNR order present, any urinary catheter use.

${ }^{1}$ Severity of Cognitive Impairment was measured by the Cognitive Performance Scale (CPS) - No/Mild (0, 1); Mild/Moderate (2, 3); Moderate/Severe (4, 5); Very Severe (6). 
severe CI are described as "comatose" or showing "no discernible consciousness", these patients may be physically unable to become agitated. In contrast, patients with severe CI may become agitated during intercurrent illness, prompting transfers to the ED. Evidence suggests that a frequent precipitant for acute care transfers is dementiarelated behavioral issues [48], which are commonly exacerbated with acute medical illness.

In contrast to our ED visit results, we found that hospitalizations did not vary significantly by degree of CI. Our results may reflect the fact that the decision to hospitalize is often based on more data such as lab tests and radiology results which often do not account for CI. In contrast, the initial decision to transfer a $\mathrm{NH}$ resident for an ED evaluation is based more on overall clinical impression that may implicitly incorporate a patient's cognitive status. Alternatively, the presence of CI may actually cloud the ability of nursing staff to appropriately recognize the nature and severity of a change in health status. As a result, nursing staff may err on the side of transferring residents to the hospital for conditions that could be potentially managed in the $\mathrm{NH}$.

Our ACS results suggest that severity of $\mathrm{CI}$ has a significant effect on rates of potentially preventable, or ACS, ED visits, but little effect on ACS hospitalizations. NH residents with no/mild CI (CPS 0-1, MMSE = 22-25) and severe CI (CPS 4-5, MMSE =5-7) have significantly higher rates of ACS ED visits than those with moderate CI (CPS 2-3, MMSE = 15-19) or very severe CI (CPS 6, MMSE =0-4), the latter of which is the population typically studied in this body of literature. While families and caregivers may prefer more aggressive care for acute medical problems in the earlier stages of $\mathrm{CI}$, our findings suggest that the very presence of even mild CI in a NH resident with a FT may increase the risk of a potentially preventable ED visit. Prior research suggests that family members of $\mathrm{NH}$ residents with dementia are often unsure about the length and expected course of the illness and such uncertainty makes it difficult to determine whether an acute illness is part of a downward trajectory or a temporary, reversible setback [49].

For many cognitively impaired NH residents, a transfer to the hospital or ED likely represents a significant burden. This frail, vulnerable population is often easily confused, frustrated and frightened; tends to exhibit behavioral and psychiatric disturbances when under stress; and is often unable to communicate their needs or understand care instructions. Given the fast-paced nature of the ED and focus on rapid triage and treatment, many cognitively impaired patients may not understand why they are moved from their familiar surroundings to a strange setting with unfamiliar caregivers who must perform uncomfortable procedures such as venipuncture or FT reinsertion. Moreover, hospital transfers in this population frequently results in greater cognitive and functional decline, delirium, iatrogenic complications and death [16,17]. Thus, our finding that one in four tube-fed $\mathrm{NH}$ residents require hospitalization or ED visits likely represents a substantial burden for this vulnerable cognitively impaired population.

There is growing recognition of the unique and important role ED care providers can play in supporting early palliative care interventions along a patient's disease trajectory, promoting quality of life, as well as reducing treatment costs [50-54]. Recent studies indicate that palliative interventions in the ED may improve timely provision of care, improve care outcomes, increase direct referrals to hospice, decreased lengths of stay, improve patient and family satisfaction, and reduce intensive care utilization, as well as health care costs [55-57]. Additional research is needed to evaluate the effect of such interventions with frail $\mathrm{NH}$ residents, such as those with feeding tubes and CI, who may frequently visit the ED.

Our results should be interpreted in light of our study's limitations. First, we relied on administrative data and therefore lacked detailed clinical information regarding causes of ED and hospital visits. This also limited our ability to account for individual clinical characteristics. However, we were able to rely on validated scales and frequently used MDS resident-level variables to risk adjust our outcomes. Second, we were unable to determine the indication for FT placement. It is possible that some residents with moderate/severe or very severe CI received a FT for nutritional support after a stroke, trauma, or head or neck cancer for which there is some data to suggest FTs may lead to better outcomes $[14,41,58]$. Third, by focusing only on residents with FTs we may have selected for a population with an inherent preference towards more aggressive care, including transfers to the acute care hospital. Despite these limitations, this is the first study to describe rates of hospitalization and ED visits, including for potentially preventable conditions, among a national random sample of $\mathrm{NH}$ residents with FTs and different levels of CI.

\section{Conclusion}

This study revealed that ED visits and hospitalizations are common in this vulnerable population and a significant proportion of both ED visits and hospitalizations are potentially preventable. These potentially unnecessary care transitions may lead to a premature cascade of excess disability, with higher rates of morbidity and mortality, decreased quality of life and higher health care costs. Such risks should be considered in the decision making process regarding the placement of FTs in persons with $\mathrm{CI}$ and palliative care interventions should be evaluated for those with frequent ED visits. 


\section{Abbreviations}

ACS: Ambulatory care sensitive; ADL: Activities of daily living; AHRQ: Agency for healthcare research and quality; CHESS: Changes in health end-stage disease and symptoms and signs; Cl: Cognitive impairment; CMS: Centers for medicare and medicaid services; CPS: Cognitive performance scale; ED: Emergency department; FT: Feeding tube; IRR: Incident rate ratio; MDS: Minimum data set; MEDPAR: Medicare provider analysis and review; MMSE: Mini mental status exam; NH: Nursing home; PQI: Prevention quality indicator; SAF: Standard analytic file.

\section{Competing interests}

The authors declare that they have no competing interests.

\section{Authors' contributions}

CS conceptualized and designed the study; acquired, analyzed and interpreted the data; and drafted the manuscript. NS and PG participated in the study design and coordination; helped interpret the data; and draft the manuscript. SL helped conceptualize and design the study; analyze and interpret data; and draft the manuscript. All authors read and approved the final manuscript.

\section{Acknowledgments}

We would like to thank Dr. Alan Bostrom for his programming and statistical support. This work was supported by the John A. Hartford Foundation/ Atlantic Philanthropies Claire M. Fagin and the National VA Quality Scholars postdoctoral fellowship programs (Dr. Stephens), as well as the UCSF CTSI KL2 Career Development Award program (8 KL2 TR000143-08; Dr. Stephens). Other funding sources for authors include: K08 HS 017965 Agency of Healthcare Research and Quality and the UCSF CTSI-K Program (supported by NIH/NCRR UCSF-CTSI grant UL1 RR024131; Dr. Govindarajan); Beeson Career Development Award from the NIA and American Federation of Aging Research (K23AG040779) and SD Bechtel Jr Foundation Award (Dr. Lee). No funding agencies for the authors had a role in the design, execution, analysis, and interpretation of the data, or writing of the study.

\section{Author details}

${ }^{1}$ Department of Community Health Systems, University of California San Francisco, 2 Koret Way, \#N531E, San Francisco, CA 94143-0608, USA. ${ }^{2}$ Division of Geriatrics, Palliative \& Extended Care, UCSF/San Francisco VA Medical Center, 4150 Clement St, San Francisco, CA 94121, USA. ${ }^{3}$ UC Berkeley/UCSF Joint Medical Program, 570 University Hall \#1190, Berkeley, CA 94720, USA. ${ }^{4}$ Department of Emergency Medicine, University of California San Francisco, 505 Parnassus Ave, San Francisco, CA 94143, USA.

Received: 14 October 2013 Accepted: 7 March 2014

Published: 20 March 2014

\section{References}

1. U.S. Department of Health and Human Services, Centers for Medicare and Medicaid Services: Nursing Home Data Compendium. 2010. http://www.cms. gov/Medicare/Provider-Enrollment-and-Certification/Certificationand Complianc/Downloads/nursinghomedatacompendium_508.pdf.

2. Hebert LE, Scherr PA, Bienias JL, Bennett DA, Evans DA: Alzheimer disease in the U.S. population: Prevalence estimates using the 2000 Census. Arch Neurol 2003, 60(8):1119-1122.

3. Givens JL, Selby K, Goldfeld KS, Mitchell SL: Hospital transfers of nursing home residents with advanced dementia. J Am Geriatr Soc 2012, 60(5):905-909.

4. Stephens C, Blegen M, Newcomer, Blegen M, Miller B, Harrington C: Emergency department use by nursing home residents: Effect of severity of cognitive impairment. Gerontologist 2012, 52(3):383-393.

5. Carter MW, Porell FW: Vulnerable populations at risk of potentially avoidable hospitalizations: The case of nursing home residents with Alzheimer's disease. Am J Alzheimers Dis Other Demen 2005, 20:349-358.

6. Hanson LC, Ersek M, Gilliam R, Carey TS: Oral feeding options for people with dementia: a systematic review. J Am Geriatr Soc 2011, 59(3):463-472.

7. Finucane TE, Christmas $C$, Travis $K$ : Tube feeding in patients with advanced dementia: a review of the evidence. JAMA 1999, 282(14):1365-1370.
8. Grant MD, Rudberg MA, Brody JA: Gastrostomy placement and mortality among hospitalized Medicare beneficiaries. JAMA 1998, 279(24):1973-1976.

9. Kuo S, Rhodes RL, Mitchell SL, Mor V, Teno JM: Natural history of feedingtube use in nursing home residents with advanced dementia. J Am Med Dir Assoc 2009, 10(4):264-270.

10. Teno JM, Gozalo PL, Mitchell SL, Kuo S, Rhodes RL, Bynum JP, Mor V: Does feeding tube insertion and its timing improve survival? J Am Geriatr Soc 2012. doi:10.1111/j.1532-5415.2012.04148.x.

11. Teno JM, Gozalo P, Mitchell SL, Kou S, Fulton AT, Mor V: Feeding tubes and the prevention or healing of pressure ulcers. Arch Intern Med 2012, 172(9):697-701.

12. Mitchell SL, Teno JM, Roy J, Kabumoto G, Mor V: Clinical and organizational factors associated with feeding tube use among nursing home residents with advanced cognitive impairment. JAMA 2003, 290:73-80.

13. Hanson LC, Dobbs D, Usher BM, Williams S, Rawlings J, Daaleman TP: Providers and types of spiritual care during serious illness. J Palliat Med 2008, 11(6):907-14.

14. Carey TS, Hanson LC, Garrett JM, Lewis C, Phifer N, Cox CE, Jackman A: Expectations and outcomes of gastric feeding tubes. Am J Med 2006, 119(527):e11-16.

15. Teno JM, Mitchell SL, Skinner J, Kuo S, Fisher E, Intrator O, Rhodes R, Mor V: Churning: the association between health care transitions and feeding tube insertion for nursing home residents with advanced cognitive impairment. J Palliat Med 2009, 12(4):359-62.

16. Ouslander JG, Weinberg AD, Phillips V: Inappropriate hospitalization of nursing facility residents: A symptom of a sick system of care for frail older people. J Am Geriatr Soc 2000, 48:230-231.

17. Pedone C, Ercolani S, Catani M, Maggio D, Ruggiero C, Quartesan R, Senin $U$, Mecocci $P$, Cherubini A: Elderly patients with cognitive impairment have a high risk for functional decline during hospitalization: The GIFA study. J Gerontol: Med Sci 2005, 60A:1576-1580.

18. Morris JN, Fries BE, Mehr DR, Hawes C, Phillips C, Mor V, Lipsitz LA: MDS Cognitive Performance Scale. J Gerontol 1994, 49(4):M174-82.

19. Hartmaier SL, Sloane PD, Guess HA, Kosh GG: The MDS Cognition Scale: a valid instrument for identifying and staging nursing home residents with dementia using the Minimum Data Set. J Am Geriatr Soc 1994, 42:1173-1179.

20. Teno JM, Mitchell SL, Gozalo PL, Dosa D, Hsu A, Intrator O, Mor V: Hospital characteristics associated with feeding tube placement in nursing home residents with advanced cognitive impairment. JAMA 2010, 303(6):544-550

21. Paquay L, De Lepeleire J, Schoenmakers B, Ylieff M, Fontaine O, Buntinx F: Comparison of the diagnostic accuracy of the Cognitive Performance Scale (Minimum Data Set) and the Mini-Mental State Exam for the detection of cognitive impairment in nursing home residents. Int J Geriatr Psychiatry 2007, 22(4):286-293.

22. Cohen-Mansfield J, Taylor L, McConnell D, Horton D: Estimating the cognitive ability of nursing home residents from the minimum data set. Outcomes Manag Nurs Pract 1999, 3(1):43-46.

23. Gruber-Baldini AL, Zimmerman SI, Mortimore E, Magaziner J: The validity of the Minimum Data Set in measuring the cognitive impairment of persons admitted to nursing homes. J Am Geriatr Soc 2000, 48:1601-1606.

24. Hartmaier SL, Sloane PD, Guess HA, Kosh GG, Madeline Mitchel C, Phillips CD: Validation of the minimum data set cognitive performance scale: Agreement with the mini-mental state examination. J Geront 1995, 50A(2):M128-M133.

25. Agency for Healthcare Research and Quality: Quality Indicator User Guide: Prevention Quality Indicators (PQI) Composite Measures. 44th edition. Columbus, Ohio: AHRQ Quality Indicators; 2012.

26. Jiang HJ WL, Potter DEB, Burgess J: Statistical Brief \#96: Potentially Preventable Hospitalizations among Medicare-Medicaid Dual Eligibles, 2008. Rockville MD: Agency for Health Care Policy and Research; 2010.

27. Tang N, Stein J, Hsia RY, Maselli JH, Gonzales R: Trends and characteristics of U.S. emergency department visits, 1997-2007. JAMA 2010, 304(6):664-670.

28. Brownell J, Wang J, Smith A, Stephens C, Hsia R: Trends in emergency department visits for ambulatory care sensitive conditions by elderly nursing home residents, 2001-2010. JAMA Int Med 2014, 174(1):157-159.

29. Billings J, Zeitel L, Lukomnik J, Carey TS, Blank AE, Newman L: Impact of socioeconomic status on hospital use in New York City. Health Aff (Millwood) 1993, 12(1):162-173. 
30. National Research Council: Access to Health Care in America. Washington, DC: The National Academies Press; 1993.

31. Carter MW, Datti B, Winters JM: ED visits by older adults for ambulatory care-sensitive and supply-sensitive conditions. Am J Emerg Med 2006, 24(4):428-434

32. Culler SD, Parchman ML, Przybylski M: Factors related to potentially preventable hospitalizations among the elderly. Med Care 1998, 36(6):804-817.

33. Gruneir A, Bell CM, Bronskill SE, Schull M, Anderson GM, Rochon PA: Frequency and pattern of emergency department visits by long-term care residents-a population-based study. J Am Geriatr Soc 2010, 58(3):510-517.

34. Carter MW, Porell FW: Variations in hospitalization rates among nursing home residents: The role of facility and market attributes. Gerontologist 2003, 43:175-191.

35. Intrator O, Mor $\mathrm{V}$ : Effect of state Medicaid reimbursement rates of hospitalizations from nursing homes. J Am Geriatr Soc 2004, 52(3):393-398.

36. Intrator O, Zinn J, Mor V: Nursing home characteristics and potentially preventable hospitalizations of long-stay residents. J Am Geriatr Soc 2004, 52:1730-1736

37. Porell FW, Carter M: Discretionary hospitalization of nursing home residents with and without Alzheimer's disease: A multi-level analysis. J Aging Health 2005, 17:207-238.

38. Intrator O, Grabowski DC, Zinn J, Schleinitz M: Hospitalization of nursing home residents: the effects of states' Medicaid payment and bed-hold policies. Health Serv Res 2007, 42(4):1651-1671.

39. Gruneir A, Miller SC, Intrator O, Mor V: Hospitalization of nursing home residents with cognitive impairments: The influence of organizational features and state policies. Gerontologist 2007, 47:447-456.

40. Hirdes JP, Frijters DH, Teare GF: The MDS-CHESS scale: A new measure to predict mortality in institutionalized older people. J Am Geriatr Soc 2003 51:96-100.

41. Mitchell SL, Berkowitz RE, Lawson FM, Lipsitz LA: A cross-national survey of tube-feeding decisions in cognitively impaired older persons. J Am Geriatr Soc 2000, 48(4):391-397.

42. Mitchell SL, Tetroe JM: Survival after percutaneous endoscopic gastrostomy placement in older persons. J Gerontol A Biol Sci Med Sci 2000, 55:M735-739.

43. Mitchell SL, Kiely DK, Lipsitz LA: The risk factors and impact on survival of feeding tube placement in nursing home residents with severe cognitive impairment. Arch Intern Med 1997, 157(3):327-332.

44. Meier DE, Ahronheim JC, Morris J, Baskin-Lyons S, Morrison S: High shortterm mortality in hospitalized patients with advanced dementia: Lack of benefit of tube feeding. Arch Intern Med 2001, 161(4):594-599.

45. Murphy LM, Lipman TO: Percutaneous endoscopic gastrostomy does not prolong survival in patients with dementia. Arch Intern Med 2003, 163(11):1351-1353.

46. Candy B, Sampson EL, Jones L: Enteral tube feeding in older people with advanced dementia: Findings from a Cochrane systematic review. Int J Pall Nurs 2009, 15(8):396-404.

47. Braun UK, Kunik ME, Rabeneck L, Beyth RJ: Malnutrition in patients with severe dementia: Is there a place for PEG tube feeding? Ann Long Term Care 2001, 9(9):47-55.

48. Perry M, Cummings J, Jacobson G, Neuman T, Juliette C: To Hospitalize or not to Hospitalize? Medical Care for Long Term Care Facility Residents. Menlo Park, CA: Henry J. Kaiser Family Foundation; 2010:1-13.

49. Lopez RP: Doing what's best: decisions by families of acutely ill nursing home residents. W J Nurs Res 2009, 31:613-626.

50. Quest T, Asplin B, Cairns C, Hwang U, Pines JM: Research priorities for palliative and end-of-life care in the emergency setting. Acad Emerg Med 2011, 18:e70-e76.

51. Lamba S: Early goal-directed palliative therapy in the emergency department: a step to move palliative care upstream. J Palliat Med 2009, 12:767.

52. Penrod J, Deb P, Dellenbaugh C, Burgess JF, Zhu CW, Christiansen CL, Luhrs CA, Cortez T, Livote E, Allen V, Morrison S: Hospital-based palliative care consultation: Effects on hospital cost. J Palliat Med 2010, 13:973-977.

53. ACEP Emergency Medicine Practice Committee: Emergency Department Palliative Care: Information Paper. 2012. http://www.acep.org/uploadedFiles/ ACEP/Practice_Resources/issues_by_category/administration/Palliative_ Care_IP Final_June2012 edited.pdf.
54. Stone S: Emergency department research in palliative care: Challenges in recruitment. J Palliat Med 2009, 12:867-868.

55. Meier D, Beresford L: Fast response is key to partnering with the emergency department. J Palliat Med 2007, 10:641-645.

56. Beemath A, Zalenski R: Palliative emergency medicine: Resuscitating comfort care? Ann Emerg Med 2009, 54:103-104.

57. Penrod J, Deb P, Luhrs C, Dellenbaugh C, Zhu CW, Hochman T, Maciejewski $\mathrm{ML}$, Granieri E, Morrison S: Cost and utilization outcomes of patients receiving hospital-based palliative care consultation. J Palliat Med 2006, 9:855-860.

58. James R, Gines D, Menlove A, Horn SD, Gassaway J, Smout RJ: Nutrition support (tube feeding) as a rehabilitation intervention. Arch Phys Med Rehabil 2005, 86:S82-592.

doi:10.1186/1471-2318-14-35

Cite this article as: Stephens et al:: Emergency department visits and hospitalizations by tube-fed nursing home residents with varying degrees of cognitive impairment: a national study. BMC Geriatrics 2014 14:35

\section{Submit your next manuscript to BioMed Central and take full advantage of:}

- Convenient online submission

- Thorough peer review

- No space constraints or color figure charges

- Immediate publication on acceptance

- Inclusion in PubMed, CAS, Scopus and Google Scholar

- Research which is freely available for redistribution 